(ACPA+ve vs ACPA-ve vs PsA) and pathotypes (fibroid, myeloid and lymphoid) (table1) we demonstrated a significantly higher prevalence of a lymphoid pathotype in ACPA+ve RA vs ACPA-ve or PsA.

\begin{tabular}{|c|c|c|c|c|c|c|c|}
\hline & $\begin{array}{c}\text { RA acpa + } \\
\text { N90 } \\
\text { 9ungraded }\end{array}$ & $\begin{array}{l}\text { RA acpa- } \\
\text { N55 } \\
\text { 12ungraded }\end{array}$ & $\begin{array}{c}\text { PsA } \\
\text { N41 } \\
\text { Oungraded }\end{array}$ & $\begin{array}{c}P \text { value } \\
\text { fisher } \\
\text { test }\end{array}$ & $\begin{array}{c}P \text { value } \\
\text { acpa+vs } \\
\text { acpa- }\end{array}$ & $\begin{array}{c}P \text { value } \\
\text { acpa+vs } \\
\text { PsA }\end{array}$ & $\begin{array}{c}P \text { value } \\
\text { acpa- vs } \\
\text { PsA }\end{array}$ \\
\hline $\mathbf{F}$ & 15 (16\%) & 17 (31\%) & 15 (36\%) & $0.01^{*}$ & $0.03^{\star}$ & $0.005^{\star}$ & 0.41 \\
\hline M & 25 (28\%) & $14(25 \%)$ & $11(27 \%)$ & & & & \\
\hline L & $41(45 \%)$ & $12(22 \%)$ & $10(24 \%)$ & & & & \\
\hline
\end{tabular}
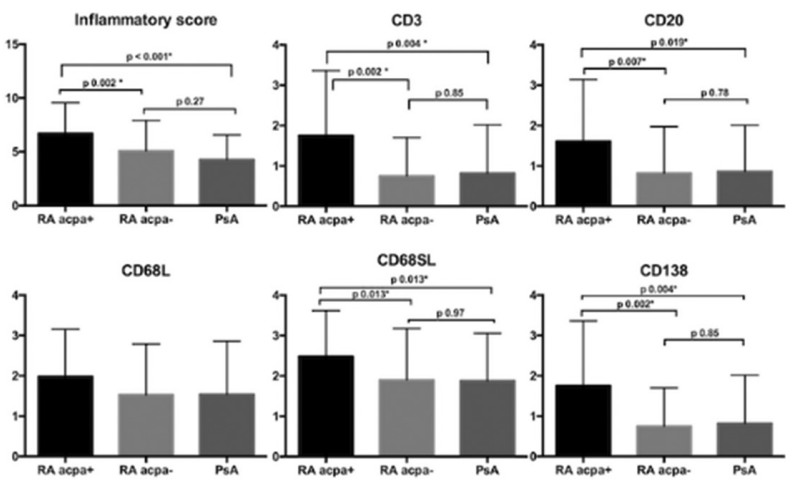

Conclusions: Our results suggest that the synovial cell infiltrate (B cells, T cells, macrophages and plasma cells) in ACPA-ve RA is significantly different from ACPA +ve patients. They also suggest shared pathophysiological mechanisms between PsA and ACPA-ve RA and support a role for future refinement of diagnosis of ACPA-ve RA according to synovial pathobiology.

Disclosure of Interest: None declared

DOI: 10.1136/annrheumdis-2018-eular.3489

\section{OP0041 DOES TREATMENT STRATEGY INFLUENCE THE ABILITY TO ACHIEVE AND SUSTAIN DMARD-FREE REMISSION IN RA?; RESULTS OF A LONGITUDINAL STUDY COMPARING AN INTENSIVE DAS-STEERED TREATMENT STRATEGY WITH TREAT-TO-TARGET IN ROUTINE CARE}

L.E. Burgers ${ }^{1}$, J.A. van der Pol${ }^{2}$, T.W.J. Huizinga ${ }^{1}$, C.F. Allaart ${ }^{1}$, A.H.M. van der Helm-van Mil ${ }^{1}{ }^{1}$ Rheumatology, ${ }^{2}$ Leiden University Medical Centre, Leiden, Netherlands

Background: Disease-modifying anti-rheumatic drug (DMARD)-free remission is an achievable outcome in rheumatoid arthritis (RA). The influence of treatment strategy on the ability to achieve and sustain this outcome is unclear. Therefore, we compared the prevalence and sustenance of DMARD-free remission in RApatients treated in a trial with intensive DAS-steered care aimed at DMARD-free remission versus RA-patients treated to target in routine care.

Methods: 279 consecutive RA-patients (2010-criteria), diagnosed in the Leiden University Medical Centre between March 2007-September 2010, were studied. Of these, 155 participated in a DAS $<1.6$ steered trial aimed at DMARD-free remission (IMPROVED-study). These patients were initially treated with highdose prednisone $(60 \mathrm{mg} /$ day) and methotrexate. Medication was intensified in case of a DAS $>1.6$ and tapered in case of a DAS $<1.6$. The other 124 RApatients were treated according to routine care, consisting of initial methotrexate and subsequent DAS $<2.4$ steered treatment. The median follow-up was 7.8 years. Medical records were studied on achieving DMARD-free remission, defined as the absence of synovitis for $\geq 1$ year after DMARD-cessation, and 'late flares', defined as recurrence of clinical synovitis $\geq 1$ year after DMARD-cessation. Sustained DMARD-free remission was defined as the sustained absence of clinical synovitis after DMARD-cessation for $\geq 1$ year and the total follow-up duration; i.e. patients with a late flare were not in this group. Percentages of remission and late flares were compared between the two treatment strategies, in all patients and after stratification by ACPA.

Results: Patients receiving intensive treatment were more often ACPA-positive ( $59 \%$ vs $40 \%$ ). DMARD-free remission was achieved by $35 \%$ of patients receiving intensive treatment and by $29 \%$ of patients receiving routine care (HR 1.2, 95\% Cl: 0.8 to 1.8). Within the ACPA-positive and ACPA-negative strata patient characteristics were similar, except for a younger age in patients receiving intensive treatment. Within ACPA-positive patients, DMARD-free remission was achieved more often in the intensive treatment group than in the routine care group (25\% vs 6\%, HR 4.9, 95\%: Cl: 1.4 to 17 , corrected for age). In ACPA-negative patients no differences were observed ( $49 \%$ vs $44 \%, \mathrm{HR} 1.1,95 \% \mathrm{Cl}: 0.6$ to
1.8 , corrected for age). A late flare occurred in $20 \%$ of patients receiving intensive treatment and in $8 \%$ of patients receiving routine care $(\mathrm{HR} 2.3,95 \% \mathrm{Cl}: 0.6$ to 8.3). After excluding late flares from the remission group, the prevalence of DMARD-free sustained remission was not different for both treatment strategies in the total group ( $28 \%$ vs $27 \%$, HR $1.0,95 \%$ Cl: 0.6 to 1.5$)$. Also in the ACPA-positive group no significant effect remained $(17 \%$ vs $6 \%$, HR $3.1,95 \% \mathrm{Cl}: 0.9$ to 11 , corrected for age).

Conclusions: An intensive treatment strategy was not associated with a higher prevalence of DMARD-free sustained remission compared to up-to-date routine treatment. Within ACPA-positive RA, intensive treatment resulted in more remission but also in more late flares. Together these data do not provide evidence to prioritise the studied intensive treatment strategy above current routine care.

Disclosure of Interest: None declared

DOI: 10.1136/annrheumdis-2018-eular.4698

\section{OP0042 IN ACPA POSITIVE AT-RISK INDIVIDUALS, WHICH MR AND US FINDINGS BEST PREDICT DEVELOPMENT OF CLINICAL SYNOVITIS?}

L. Hunt, J. Nam, E.M. Hensor, K. Mankia, E. Rowbotham, A.J. Grainger, P. Emery. Leeds Institute of Rheumatic and Musculoskeletal Medicine and NIHR Leeds Biomedical Research Centre, LTHT, Leeds, UK

Background: ACPA +individuals with non-specific MSK symptoms are at risk of inflammatory arthritis (IA) and may benefit from early intervention. Clinical, serological and US markers have previously been assessed to determine risk of progression. ${ }^{1}$

Objectives: Evaluate the value of MR and US imaging in characterising and quantifying risk in a large ACPA + cohort.

Methods: Eligible ACPA +individuals without clinical synovitis had gadolinium enhanced 3.0 T MRI of the dominant hand and wrist. Images were scored by 2 radiologists for synovitis, bone marrow oedema (BME), erosions and tenosynovitis (TSV) according to OMERACT RAMRIS. Joint counts for each abnormality at each joint were corrected for age using a healthy controls reference range. ${ }^{2}$ US of the same regions were scored using OMERACT definitions. Maximum MRI and US abnormality scores observed per patient across all joints scored were dichotomised $<2, \geq 2$. Potential associations between baseline US (greyscale (GS) and powerDoppler (PD)) and MRI findings and i) progression to IA and ii) development of clinical synovitis within a joint were identified using Cox and penalised regression.

Results: Imaging of 98 individuals (mean age 47, 69\% female) was available. $30 \%$ (29/98) progressed to IA. Median time to progression was 31 weeks (IQR 24 67 ). BME and erosions scores $\geq 2$ were reported in $10 \%$, preferential location to the carpal bones/wrist joints. Synovitis score $\geq 2$ was present in $9 \%$, preferential location at MCP5 and radial carpal/intercarpal joints. TSV was the most frequent reported abnormality with $22 \%$ scoring $\geq 2,40 \%$ scoring 1 . US GS and PD scores $\geq 2$ were reported in $23 \%$ and $9 \%$ respectively. The unadjusted analysis $\mathrm{HRs}$ for all imaging abnormalities were high, indicating potential association with risk of progression. Controlling for variables, MRI TSV was associated with time to IA with an increased HR. US GS and PD were also independently associated with time to progression and confirmed on penalised regression, table 1. At the joint level MRI TSV, BME and US GS were associated with the risk of progression to clinical synovitis, $\quad H R=7.03 p<0.001$, HR 4.22 $p=0.076$ and HR $8.04 \mathrm{p}<0.001$ respectively.

Abstract OP0042 - Table 1. Patient-level Cox regression proportional hazard modelling of associations between maximum observed score per patient for baseline MRI abnormalities and time to IA ( $\mathrm{n}=95)$

\begin{tabular}{|c|c|c|c|c|c|}
\hline Abnormality & $\begin{array}{l}\text { No } I A \% \\
(n=66)\end{array}$ & $\begin{array}{c}\mathrm{IA} \% \\
(\mathrm{n}=29)\end{array}$ & $\begin{array}{l}\text { Unadjusted HR } \\
(90 \% \mathrm{Cl}), \mathrm{P} \text { value }\end{array}$ & $\begin{array}{c}\text { Adjusted HR } \\
(90 \% \mathrm{Cl}), \mathrm{P} \text { value }\end{array}$ & $\begin{array}{c}\text { Penalised } \\
\text { HR }\end{array}$ \\
\hline $\begin{array}{l}\text { Small joint } \\
\text { tenderness }\end{array}$ & $44(29)$ & $55(16)$ & $\begin{array}{c}1.60(0.87,2.97) \\
p=0.207\end{array}$ & $\begin{array}{c}1.20(0.58,2.46) \\
p=0.679\end{array}$ & 1 \\
\hline $\begin{array}{l}R F \text { and/or } \\
\text { ACPA }>3 U L N\end{array}$ & $83(55)$ & $93(27)$ & $\begin{array}{c}2.14(0.64,7.16) \\
p=0.301\end{array}$ & $\begin{array}{c}1.02(0.27,3.80) \\
p=0.981\end{array}$ & 1 \\
\hline$E M S \geq 30 \mathrm{~min}$ & $27(18)$ & $45(13)$ & $\begin{array}{c}2.00(1.08,3.71) \\
p=0.064\end{array}$ & $\begin{array}{c}1.52(0.69,3.37) \\
p=0.384\end{array}$ & 1 \\
\hline US PD $\geq 2$ & $2(1)$ & $28(8)$ & $\begin{array}{c}7.21(3.62,14.36) \\
p<0.001\end{array}$ & $\begin{array}{c}5.09(1.93,13.44) \\
p=0.006\end{array}$ & 4.37 \\
\hline US GS $\geq 2$ & $11(7)$ & $52(15)$ & $\begin{array}{c}4.97(2.69,9.19) \\
\mathrm{p}<0.001\end{array}$ & $\begin{array}{c}2.69(1.14,6.34) \\
p=0.059\end{array}$ & 2.17 \\
\hline $\begin{array}{l}\text { MRI } \\
\text { erosion } \geq 2\end{array}$ & $6(4)$ & $17(5)$ & $\begin{array}{c}2.15(0.96,4.82) \\
p=0.120\end{array}$ & $\begin{array}{c}0.59(0.20,1.76) \\
p=0.431\end{array}$ & 1 \\
\hline MRI $B M E \geq 2$ & $8(5)$ & $17(5)$ & $\begin{array}{c}2.30(1.01,5.23), \\
\quad p=0.097\end{array}$ & $\begin{array}{c}1.55(0.56,4.27) \\
p=0.482\end{array}$ & 1 \\
\hline $\begin{array}{l}\text { MRI } \\
\text { synovitis } \geq 2\end{array}$ & $3(2)$ & $24(7)$ & $\begin{array}{c}4.22(2.03,8.75), \\
\quad p=0.001\end{array}$ & $\begin{array}{c}1.08(0.46,2.54), \\
p=0.881\end{array}$ & 1 \\
\hline $\mathrm{MRI} T S V \geq 2$ & $14(9)$ & $41(12)$ & $\begin{array}{c}3.51(1.89,6.55) \\
p=0.001\end{array}$ & $\begin{array}{c}4.02(1.91,8.44) \\
p=0.002\end{array}$ & 3.16 \\
\hline
\end{tabular}

